\title{
Multiple-Scale Synchrotron and Lab Source X-Ray Fluorescence 2D Mapping of Gold Mineralization Styles at the Troilus Gold Project, Frotêt-Evans Greenstone Belt, Quebec, Canada
}

Lisa Van Loon ${ }^{1}$, James Alexander ${ }^{2}$, Mac Valliant ${ }^{2}$, Adrienne Iannicca ${ }^{2}$, Natalia Goszczynski ${ }^{2}$, Tyler Beattie $^{3}$, Remy Klick ${ }^{3}$, Bertrand Brassard ${ }^{3}$, Blake Hylands ${ }^{3}$ and Neil Banerjee ${ }^{4}$

${ }^{1}$ LISA CAN Analytical Solutions Inc., United States, ${ }^{2}$ Department of Earth Sciences, Western University, United States, ${ }^{3}$ Troilus Gold Corp., United States, ${ }^{4}$ Department of Earth Sciences, University of Western Ontario, United States

Introduction: The Troilus Gold Project lies within the eastern segment of the Frotêt-Evans Greenstone Belt (FEGB) and is located approximately $120 \mathrm{~km}$ north of Chibougamau in central Quebec, Canada. The property includes the past producing Troilus Mine, which was an open pit that produced over two million ounces of gold and approximately 70,000 tonnes of copper. The FEGB is largely dominated by variably metamorphosed tholeiitic and magnesian basalts that occur in association with felsic and intermediate calc-alkaline pyroclastic rocks, lava flows, and local ultramafic units. Syn- to post-deformational gabbroic to monzogranitic plutonic rocks occur throughout the greenstone belt [1]. Historically, the main mineralized zones at the Troilus Property were thought to be associated with the margins of the Troilus Diorite called the Z87, Z87S, and the J zones. But more recent work by Troilus Gold Corp. has identified other important mineralized zones along the northern and southern continuity of the historic open pits named the Allongé Zone, and Southwest Zone, respectively, as well as elsewhere on their $>107,000$ ha property. Both disseminated and vein-hosted styles of gold-copper mineralization have previously been described at the Troilus deposit [1]. Gold is commonly associated with the presence of sulphides but gold and copper grade do not correlate with sulphide content. In addition to $\mathrm{Au}-\mathrm{Cu}$, minor amounts of $\mathrm{Ag}, \mathrm{Zn}$ and $\mathrm{Pb}$, as well as traces of $\mathrm{Bi}, \mathrm{Te}$, and $\mathrm{Mo}$ are also present. Current research is focussed on improving the metallogenic interpretation to aid in exploration efforts through the identification of gold mineralizing styles. The FEGB is relatively under-explored compared to other greenstone gold belts. Combining a variety of microanalysis techniques at multiple resolution scales provides a unique opportunity to identify the controls on gold mineralization that can then be applied as a tool on a larger, project-wide scale. Experimental: Representative samples of half drill core from the Z87, J, and SW Zones with high gold grades were selected. SR-XRF was performed directly on the half drill core samples without extensive sample preparation at the 8-BM beamline at Argonne National Laboratory (APS) to create 2D trace element maps that reveal spatial, textural, and mineralogical associations with gold mineralization. 2D SR-XRF maps of up to $10 \mathrm{~cm} \times 4 \mathrm{~cm}$ were produced by rastering across the sample, using a beam spot size of $500 \mu \mathrm{m}$ x $500 \mu \mathrm{m}$ with a 2.5 second dwell time. The incident X-ray energy was set to $15 \mathrm{keV}$. A Vortex 4-element SDD was used to measure the XRF signal. SR-XRF data analysis was performed with Peakaboo 5.3.0 [2]. Maps of key elements, such as $\mathrm{Fe}, \mathrm{Si}$, and $\mathrm{Au}$ were compared to investigate geochemical associations, as well as macro-scale textures and alteration patterns, and associations of Au with other elements. Following SR-XRF, thin sections were prepared from regions of interest. Optical petrography, XRF, and EPMA analyses were conducted at the Earth and Planetary Materials 
Analysis Laboratory at Western University. Optical petrography was used to identify major minerals, textures, and the alteration styles using a Nikon LV100POL microscope equipped with a Nikon DS-Ri1 digital camera. Higher resolution XRF mapping of the thin sections at $20 \mu \mathrm{m}$ resolution was conducted using a Bruker M4 Tornado XRF system equipped with a Rh X-ray source with an energy of $50 \mathrm{kV}$, a $12.5 \mathrm{~mm} \mathrm{Al}$ filter, and a SDD. The system operates under vacuum so light elements ( $>\mathrm{Na}$ ) are detectable. Finally, EPMA analysis was conducted using a JEOL JXA$8530 \mathrm{~F}$ field-emission electron microprobe on select areas of interest using $\sim 1 \mu \mathrm{m}$ resolution to resolve the relationship of Au with other elements and minerals. Results: SR-XRF of a drill core sample shows that $\mathrm{Au}$ is associated with $\mathrm{Cu}$ (chalcopyrite) and $\mathrm{Fe}$ (pyrite) within a zone of silica and $\mathrm{Ca}$ (carbonate) alteration, Figure 1. The large-scale SR-XRF mapping of drill core allows the correlation of elemental relationships of gold mineralization with mineralogical and textural features [3] and has been used to understand alteration styles in proximity to high-grade gold mineralization in other studies. [4, 5] Higher resolution mapping of the thin section further refines the spatial relationships, Figure 2. At higher resolution, the gold association with the silica and carbonate alteration is more pronounced than that with $\mathrm{Cu}$. Importantly, although $\mathrm{Au}$ and $\mathrm{Cu}$ are spatially correlated, $\mathrm{Au}$ is not identified within the chalcopyrite grains. Petrographic examination of the Southwest, Z87, and J4 zones has revealed numerous similarities in lithologies, metamorphic and alteration mineral assemblages, and ore mineralization styles. High-resolution EPMA identifies free gold grains as well as electrum and other Au alloys in quartz-carbonate veins, sometimes with sulphides in near proximity. Conclusion: Gold is found in all zones at the interstices of sulphide phases as well as in areas of silica and carbonate alteration. No gold is observed disseminated in the host rock. Electron probe microanalysis has revealed $\mathrm{AuAg}$, native $\mathrm{Bi}, \mathrm{AgTe}$, and BiSe associated with sulphides. These associations are more similar to typical orogenic gold deposits than porphyry systems. Acknowledgements: Research described in this paper was performed at the Advanced Photon Source, an Office of Science User Facility operated for the U.S. Department of Energy (DOE) Office of Science by Argonne National Laboratory, and was supported by the U.S. DOE under Contract No. DE-AC02-06CH11357, and the Canadian Light Source and its funding partners. We thank E. Maxey for support in conducting the SR-XRF experiments, Tina Hill for her assistance in using the Bruker Esprit software, Dr. G. Osinski for access to the M4 Tornado, and Marc Beauchamp for assistance with data collection. Banerjee acknowledges funding from NSERC and Troilus Gold Corporation. 

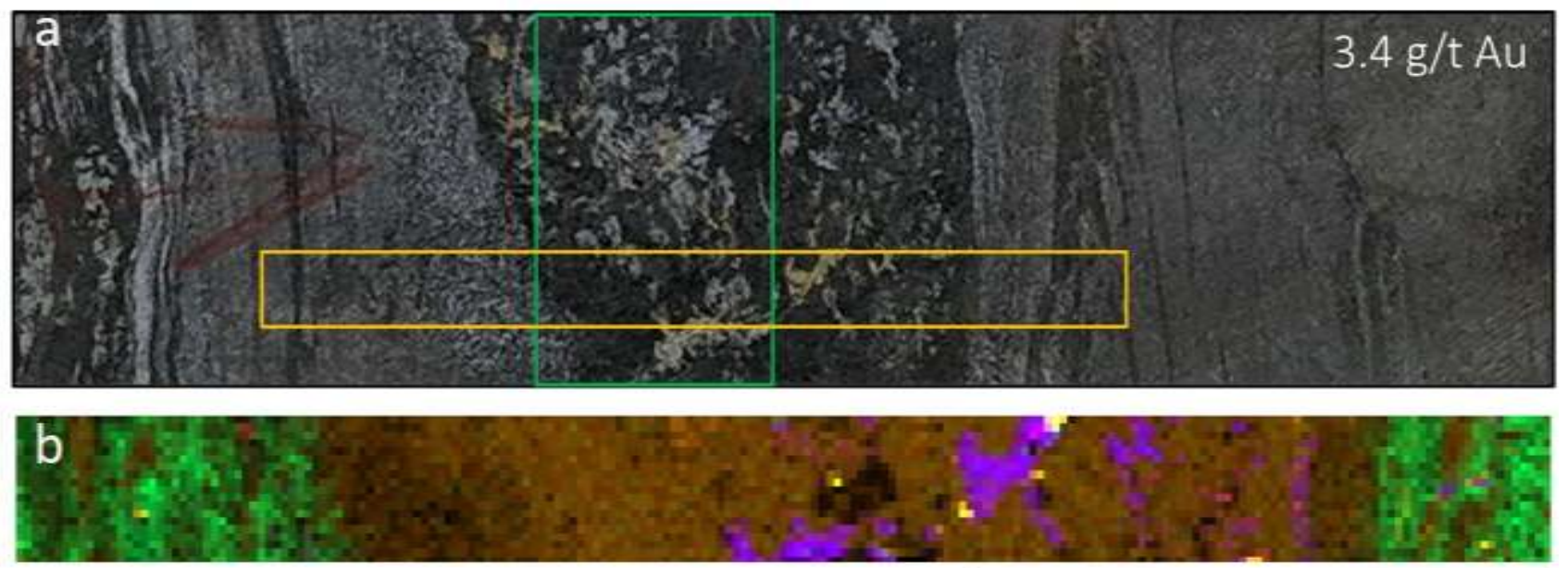

ZnK $\square$ KK $\square$ AuL $\square$ CaK $\square$ CuK

Figure 1. (a) Half drill core sample with a gold grade of $3.4 \mathrm{~g} / \mathrm{t}$. The orange rectangle is the area (10 $\mathrm{cm}$ wide) that was mapped with synchrotron XRF (shown in (b)). The area outlined in green is where the thin section was made. (b) Composite synchrotron XRF map that shows that Au (yellow) is associated with $\mathrm{Cu}$ (purple) (chalcopyrite) in a zone of $\mathrm{Si}$ and $\mathrm{Ca}$ (orange) (carbonate) alteration.

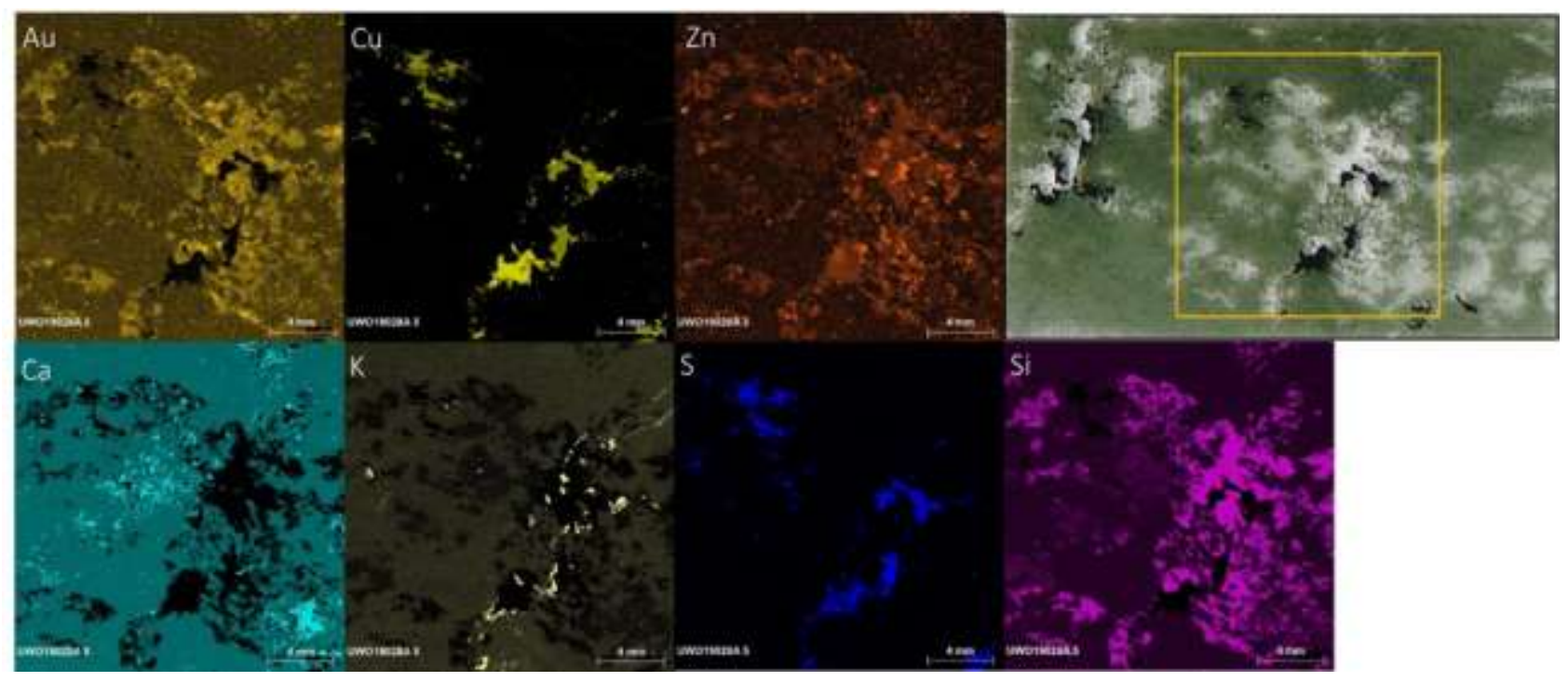

Figure 2. XRF element maps of selected elements collected using a Bruker M4 Tornado. Gold is associated with $\mathrm{Cu}$ (chalcopyrite), Fe (not shown, pyrite), and $\mathrm{Zn}$ (sphalerite) in a zone of $\mathrm{Si}$ and $\mathrm{Ca}$ (carbonate). The location of where the thin section was cut from the core sample is shown in green in Figure 1. The area of the thin section that is mapped is outlined in yellow (upper right). 


\section{References}

[1] P. Daigle, "Technical Report and Mineral Resource Estimate on the Troilus Gold-Copper Project Quebec, Canada", August, 2020, 212 p., available from https://www.troilusgold.com/_resources/pdfs/technical-report-20200827.pdf.

[2] L.L Van Loon et al., (2019). Peakaboo: Advanced software for the interpretation of X-ray fluorescence spectra from synchrotrons and other intense X-ray sources. Software Impacts, 2.

[3] N. Banerjee et al., (2018). Development of Rapid Synchrotron 2D X-ray Mapping and XANES of Rock Slabs and Drill Core as a Tool for the Mineral Exploration and Mining Industries, Microscopy \& Microanalysis 24 (S2) p.510.

[4] Casali, J., et al., (2020). Application of Large-scale Synchrotron X-Ray Fluorescence 2D Mapping of Alteration Styles to Understand Gold Mineralization at the Monument Bay Project, Stull Lake Greenstone Belt, Manitoba, Canada. Microscopy and Microanalysis, 26(S2), p.3216.

[5] Hao, C., et al., (2020). Multi-scale SR- $\mu$ XRF Imaging and Characterization of Gold Mineralization at the Monument Bay Deposit, Stull Lake Greenstone Belt, Manitoba, Canada. Microscopy and Microanalysis, 26(S2), p.1256. 